\title{
Evaluation of Oxidative Stress in Patients with Acute Lymphoblastic Leukemia: Experimental Evidence of the Efficacy of MDA as Cancer Biomarker in Young Patients
}

\author{
Mariana B. Almeida ${ }^{a}{ }_{\text {Emanuel Carrilho }}{ }^{b}$ and Suzana L. Nixdorf ${ }^{*, a}$ \\ ${ }^{a}$ Departamento de Química, Universidade Estadual de Londrina, \\ Rodovia Celso Garcia Cid, PR 445, km 380, Campus Universitário, 86057-970 Londrina-PR, Brazil \\ ${ }^{b}$ Instituto de Química de São Carlos, Universidade de São Paulo, \\ Av. Trabalhador São-Carlense, 400, 13566-590 São Carlos-SP, Brazil
}

\begin{abstract}
Acute lymphoblastic leukemia (ALL) is a fatal disorder in most cases and is the most common cancer in young patients. ALL features an uncontrolled proliferation and maturation arrest of lymphoid progenitor cells (lymphoblast) in the bone marrow. An increase of reactive species production occurs in ALL with an involvement of oxidative stress (OS) and cellular damage. However, there is a lack of information about variations in young patients. The biomarker widely used to measure the OS is the main product of lipid peroxidation, the malondialdehyde (MDA). This biomarker, when evaluated by a chromatographic method and the data analyzed by multivariate analysis with other biochemical parameters of ALL patient charts, shows the distinction of healthy and ALL patients, and a great correlation with the risk of disease.
\end{abstract}

Keywords: malondialdehyde, HPLC, principal components analysis, prognosis

\section{Introduction}

Leukemia is not the cancer with the highest incidence, however, it corresponds to the range of 25 to $35 \%$ of malignancies during childhood, and $80 \%$ of cases are diagnosed with acute lymphoblastic leukemia (ALL). In adolescents and young adults the incidence decreases to $20 \%$, and increased again over 60 years of age, however, its diagnosis is not always fast and accurate. Acute leukemia is recognized as a disease with heterogeneous characteristics and a variety of biological aspects that generally exhibit nonspecific signs or symptoms. ${ }^{1-6}$

ALL is an aggressive type of leukemia with rapid progression, being necessary the performance of an early diagnosis. It is common to find young neoplastic cells (blasts) in the morphological examination of blood and bone marrow (BM). The abnormal accumulation of blasts with lymphoid feature in the BM interrupts the production of blood cells, white blood cells, red blood cells and platelets resulting in patient BM bankruptcy and anemia, recurrent infections, bleeding, neutropenia, thrombocytopenia, and can infiltrate organs such as liver, spleen, lymph nodes, meninges, brain, and skin. ${ }^{7-10}$

*e-mail: snixdorf@uel.br
Many studies have shown high levels of lipid peroxidation in different types of cancer, including leukemia. ${ }^{11-13}$ It is known that carcinogenesis is related to three main stages: initiation, promotion and progression of tumor, however, other studies have shown that oxidative stress is involved in these three steps. ${ }^{14}$

High levels of lipid peroxidation in newly diagnosed ALL patients suggest these oxidative lesions are related to the pathogenesis and not to chemotherapy, which is quite aggressive to the organism. ${ }^{11}$ However, the number of studies on lipid peroxidation in childhood is still scarce.

The products of lipid peroxidation have been commonly used as biomarkers of oxidative damage, but the determination of oxidant agents is not feasible due to its instability. The aldehyde resulting from secondary reactions with lipids, proteins, carbohydrates and DNA have higher stability, and can be measured in plasma or urine as an indirect index of oxidative stress. Among the various aldehydes formed, malondialdehyde (MDA) is the most studied in the pathologic molecular process in oxidative stress. ${ }^{15-18}$

The commonly employed approach to analyze MDA is by the thiobarbituric acid (TBA) test, that forms the adduct $\mathrm{TBA}_{2}$-MDA which has an absorption at $532 \mathrm{~nm}$, 
allowing spectrophotometrically quantification. However, TBA reacts with a variety of oxidized lipids and aldehydes, sucrose, and urea, forming the known TBA-reactive substances (TBARS) that could cause an overestimation of the $\mathrm{TBA}_{2}-\mathrm{MDA}$ in colorimetric assay. In order to eliminate interferences, chromatographic techniques are widely used in MDA investigations, due to its selectivity and specificity, since there is a separation of $\mathrm{TBA}_{2}-\mathrm{MDA}$ from other compounds by reversed phase. ${ }^{19-21}$

Thus, the aim of this paper was to evaluate, by a selective and specific chromatographic method and multivariate analysis, the increase of oxidative stress, using MDA as biomarkers, in young patients diagnosed with ALL compared with healthy patients. Also, the relationship of the variability of biochemical and hematological parameters of ALL patient charts and the MDA values with the risk disease prognosis were considered.

\section{Experimental}

\section{Samples}

The study was reviewed and approved by the Human Ethics Committee of State University of Londrina, Paraná, Brazil (Presentation of Certificate of Appreciation for Ethics - CAAE No. 0164.0.268.000-09, protocol approved in CEP 214/09). Patients were recruited in the University Hospital of Londrina and in the Hospital of Cancer of Londrina. A term of free informed consent was signed by all participants or guardians. The studied group consisted of 18 healthy patients (HP) and 27 patients with ALL, both with age between 1 and 23 years old.

Venous blood samples were collected in $4 \mathrm{~mL}$ heparin anticoagulant tubes. The samples were placed on ice and centrifuged at $3000 \mathrm{rpm}$ at $4{ }^{\circ} \mathrm{C}$ for $10 \mathrm{~min}$, and the supernatants (plasma) were kept frozen at $-20{ }^{\circ} \mathrm{C}$ until the analysis.

\section{MDA extraction}

MDA levels were determined by the method of Bastos et al.,22 with slight modifications. Before the analysis, samples were centrifuged (MiniSpin, Interprise, Paulínia, Brazil) at $6000 \mathrm{rpm}$ for $10 \mathrm{~min}$. Eppendorf tubes containing $250.0 \mu \mathrm{L}$ of plasma, $36.0 \mu \mathrm{L}$ of $0.2 \%$ BHT (butylated hydroxytoluene; Sigma-Aldrich, Saint Louis, MO, USA) and $6.25 \mu \mathrm{L}$ of $\mathrm{NaOH}$ (sodium hydroxide; Merck, Darmstadt, Germany) $10.0 \mathrm{~mol} \mathrm{~L}^{-1}$ were vortexed. Alkaline hydrolysis of the protein bonded to MDA was achieved by incubating the mixture for $30 \mathrm{~min}$ at $60^{\circ} \mathrm{C}$ in a water bath (Fisatom 550 A, São Paulo, Brazil), and left to stand in ice bath for $10 \mathrm{~min}$. After this, $1500 \mu \mathrm{L}$ of a solution of $7.2 \%$ TCA (trichloroacetic acid; Sigma-Aldrich, Saint Louis, MO, USA) + $1 \%$ potassium iodide (KI; Quimidrol, Brazil) was added, followed by centrifugation at $6000 \mathrm{rpm}$ $(2000 \times \mathrm{g})$ for $10 \mathrm{~min}$. The supernatant $(500.0 \mu \mathrm{L})$ was transferred to screw tubes and $500.0 \mu \mathrm{L}$ of $0.6 \%$ TBA (2-thiobarbituric acid; Merck, Darmstadt, Germany) was added and incubated for $45 \mathrm{~min}$ at $90{ }^{\circ} \mathrm{C}$ in a water bath. A volume of $20.0 \mu \mathrm{L}$ was injected into the reversed phase high performance liquid chromatography with ultravioletvisible detection (RP-HPLC-UV-Vis) system.

\section{MDA standard preparation}

MDA (malondialdehyde) stock solution used to construct the calibration curve, was prepared with $22.0 \mu \mathrm{L}$ of 1,1,3,3-tetramethoxypropane (Sigma-Aldrich, Poole, $\mathrm{UK}$ ) in $10.0 \mathrm{~mL}$ of $1 \% \mathrm{H}_{2} \mathrm{SO}_{4}$ (sulfuric acid; Merck, Darmstadt, Germany). After $2 \mathrm{~h}$ protected from light, $5.0 \mu \mathrm{L}$ of this MDA stock solution were added to $1.5 \mathrm{~mL}$ of $1 \% \mathrm{H}_{2} \mathrm{SO}_{4}$. The concentration of the MDA stock solution was determined by reading the absorbance at $245 \mathrm{~nm}$ in the spectrophotometer $\left(\varepsilon_{245}=13700 \mathrm{~L} \mathrm{~mol}^{-1} \mathrm{~cm}^{-1}\right){ }^{22}$

MDA calibration curves used for quantification were performed with a pool of plasma samples of healthy patients $(n=6)$ to have a representative variance by adding the standard solution to reach the final concentrations of MDA $\left(0.00,0.25,0.50,1.00,1.50,2.00\right.$ and $\left.5.00 \mu \mathrm{mol} \mathrm{L}^{-1}\right)$, following the same procedure of MDA extraction described previously. The standard addition method on pool plasma was chosen to minimize the matrix effect.

\section{Chromatographic method}

Liquid chromatographic system was an Alliance e2695 (Waters, Milford, MA, USA) consisting of a pump with quaternary solvent organizer and degas module, autosampler, column oven and a photodiode array detector (2998 PDA), all managed by Empower 2 software. For the analysis, we used an isocratic mobile phase based on Bastos et al. ${ }^{22}$ that consisted of $35 \% \mathrm{CH}_{3} \mathrm{OH}$ (methanol; J.T. Baker, Philipsburg, NJ, USA) and $65 \%$ potassium phosphate (Nuclear, Diadema, São Paulo, Brazil) buffer (10.0 mmol L ${ }^{-1}$, pH 7.0) filtered through a $0.22 \mu$ m nylon membrane (Millipore, Merck KGaA, Darmstadt, Germany)

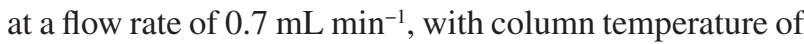
$30{ }^{\circ} \mathrm{C}$. The PDA was set at $532 \mathrm{~nm}$ for the detection of the adduct of TBA-MDA. Guard column $(4.6 \times 12.5 \mathrm{~mm}, 5 \mu \mathrm{m})$ and analytical column was a Zorbax Eclipse XDB-C18 $(4.6 \times 250 \mathrm{~mm}, 5 \mu \mathrm{m}$, Agilent Technologies, Santa Clara, USA). 


\section{Validation process}

The validation of the method was performed according to the criteria proposed by Brazilian Health Surveillance Agency (ANVISA RE 899/03). ${ }^{23}$ The following parameters were evaluated: dynamic range, linearity, limits of detection (LOD) and quantitation (LOQ), precision (repeatability and intermediate precision), accuracy (recovery) and selectivity. Robustness evaluation of chromatographic method was performed by slight modification of mobile phase flow rate ( 0.6 and $0.8 \mathrm{~mL} \mathrm{~min}^{-1}$ ), methanol concentration in the mobile phase (30 and $40 \%$ ) and column temperature $\left(25\right.$ and $\left.40{ }^{\circ} \mathrm{C}\right)$.

\section{Other biochemical parameters}

Leukocytes $\left(\mathrm{mm}^{3}\right)$, percentage of blasts $(\%)$, erythrocyte $\left(\mathrm{mm}^{3}\right)$, hemoglobin $\left(\mathrm{g} \mathrm{dL}^{-1}\right)$ and platelets $\left(\mathrm{mm}^{3}\right)$ were determined using routine clinical assays. The data were obtained from the patients' charts.

\section{Statistical analysis}

Data are presented as mean \pm standard deviation. One-way analysis of variance (ANOVA) was used to analyze the differences between the groups of patients: healthy (HP) and acute lymphoblastic leukemia (ALL). The mean comparison test (Tukey's test, at 5\% significance level) was also used. The results were also evaluated using principal component analysis (PCA) and hierarchical cluster analysis (HCA). The hierarchical tree was obtained by unweighted pair-group average as the linkage rule and considering the Euclidean distances as the coefficient of similarity. Statistical analyses were performed using the Statistica 7.0 software ${ }^{24}$ and MATLAB. ${ }^{25}$

\section{Results and Discussion}

The advantages of using a chromatographic method are the increase of sensibility and specificity. Biological samples analysis usually needs the use of buffer to maintain the $\mathrm{pH}$ of solution during analysis. However, when the blend of mobile phase (aqueous and organic) is made by the system, the buffer concentration should be lower than $25 \mathrm{mmol} \mathrm{\textrm {L } ^ { - 1 }}$ to avoid precipitation. ${ }^{26}$ The original chromatographic method ${ }^{22}$ used a high concentration of phosphate buffer $\left(50 \mathrm{mmol} \mathrm{L}^{-1}\right)$ as mobile phase. Therefore, a concentration of $10.0 \mathrm{mmol} \mathrm{L}^{-1}$ was proposed and resulted in a shorter retention time for the MDA, without compromising the resolution and selectivity.

In order to evaluate the robustness of the new method, small changes in the flow rate, organic composition of mobile phase and temperature of column were made, as described in Validation process section. No significant differences $(p>0.05)$ were observed in peak areas for these conditions. The selectivity was observed by the absence of analytical response at the same retention time of MDA when the sample diluent was injected. The peak purity of the aldehyde in the standard (Figure 1) and in the samples (data not shown) was confirmed by spectral homogeneity.

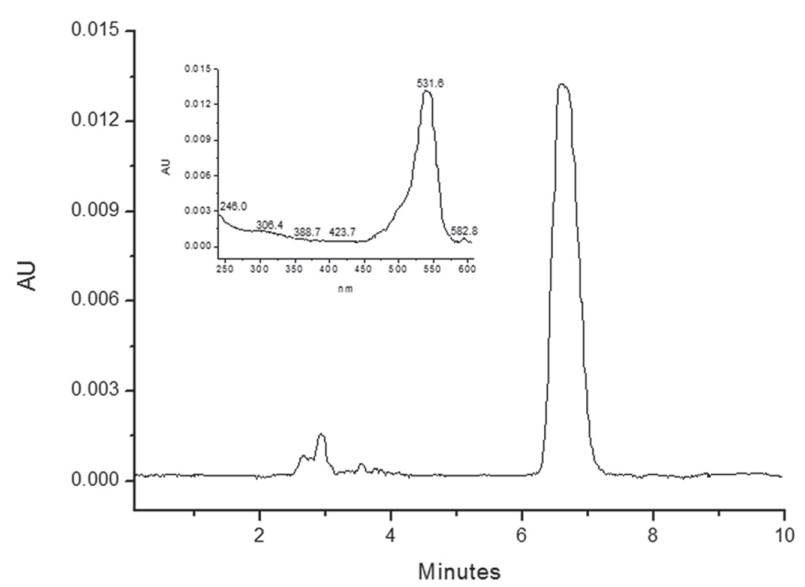

Figure 1. Chromatogram of reversed phase high performance liquid chromatography with ultraviolet-visible detection (RP-HPLC-UV-Vis) and (inset) UV-Vis spectrum of malondialdehyde (MDA) standard spiked in plasma sample. Mobile phase: methanol:potassium phosphate buffer $\left(10.0 \mathrm{mmol} \mathrm{L}^{-1}, \mathrm{pH} 7.0\right)(35: 65, \mathrm{v} / \mathrm{v})$; flow rate: $0.7 \mathrm{~mL} \mathrm{~min}^{-1}$; injection volume: $20 \mu \mathrm{L}$; column: Zorbax Eclipse XDB-C18 $(4.6 \times 250 \mathrm{~mm}, 5 \mu \mathrm{m})$; oven temperature: $30^{\circ} \mathrm{C}$; PDA at $\lambda 532 \mathrm{~nm}$.

A method validation was also performed. Table 1 shows the chromatographic parameters obtained. Based on three calibration curves, it was possible to determine the linearity,

Table 1. Chromatographic parameters from analytical method validation for MDA determination by RP-HPLC-UV-Vis

\begin{tabular}{lcc}
\hline Parameter & $\begin{array}{c}\text { MDA / } \\
\left(\mu \mathrm{mol} \mathrm{L}{ }^{-1}\right)\end{array}$ & Result \\
\hline Dynamic range & $0.00-5.00$ & - \\
Linearity (r) & & 0.9964 \\
Linear equation & $\mathrm{y}=15597 \mathrm{x}+1407.7$ \\
LOD / $\left(\mu \mathrm{mol} \mathrm{L}^{-1}\right)$ & 0.20 \\
LOQ / $\left(\mu \mathrm{mol} \mathrm{L}^{-1}\right)$ & 0.66 \\
Precision (repeatability $(\mathrm{n}=6)$, & & 3.10 \\
RSD / \%) & & \\
Intermediate precision $(\mathrm{n}=6$, & & 3.62 \\
RSD / \%) & & \\
Accuracy (recovery test / \%, & 0.25 & 103.0 \\
$\mathrm{n}=3$ ) & 2.50 & 109.1 \\
& 5.00 & 109.4 \\
\hline
\end{tabular}

MDA: malondialdehyde; RP-HPLC-UV-Vis: reversed phase high performance liquid chromatography with ultraviolet-visible detection; r: correlation coefficient; LOD: limit of detection; LOQ: limit of quantitation; n: number of replicates; RSD: relative standard deviation. 


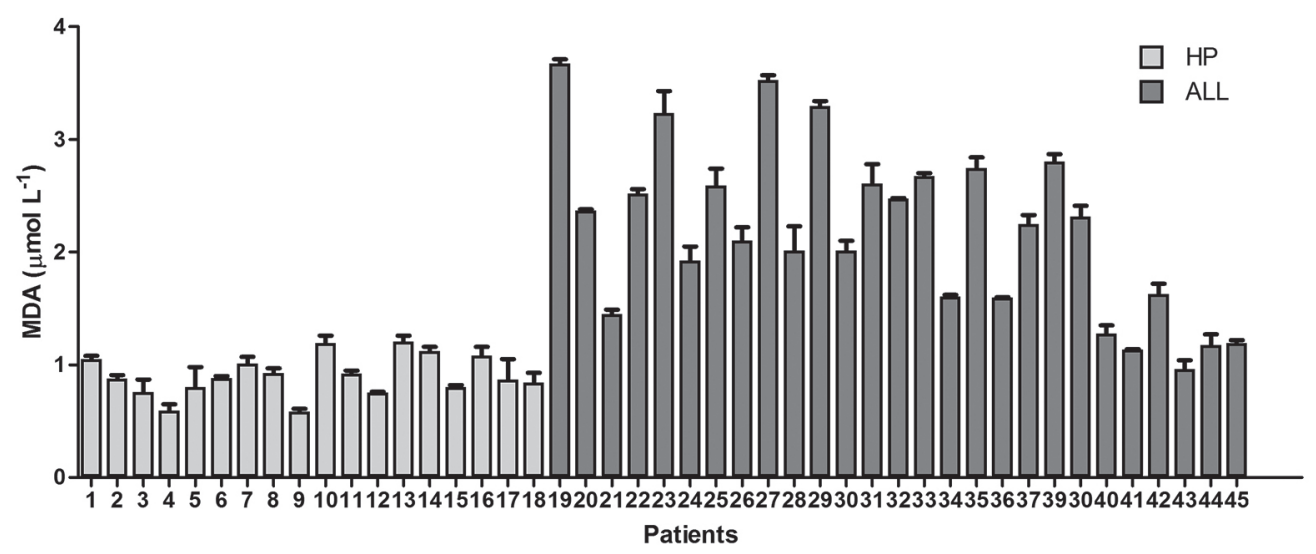

Figure 2. MDA levels in healthy (HP) and acute lymphoblastic leukemia (ALL) patients, measured by RP-HPLC-UV-Vis (reversed phase high performance liquid chromatography with ultraviolet-visible detection) method. The error bars indicates standard deviation measured from $\mathrm{n}=2$.

LOD and LOQ. The repeatability was an average of six consecutive injections, and the accuracy was determined from recovery tests performed by spiking the sample with MDA standard solutions in order to obtain low, medium and high concentration levels made in triplicate.

After validation, MDA measurement was performed on plasma samples. The variation in oxidative stress between HP and ALL was significantly altered. The MDA levels in the control group (HP, healthy patients) presented values from 0.58 to $1.20 \mu \mathrm{mol} \mathrm{L} \mathrm{L}^{-1}$ and a mean value of $0.91 \pm 0.18 \mu \mathrm{mol} \mathrm{L}^{-1}$. However, for ALL group, the MDA levels ranged from 0.97 to $3.67 \mu \mathrm{mol} \mathrm{L^{-1 }}$, with a mean value of $2.17 \pm 0.77 \mu \mathrm{mol} \mathrm{L}^{-1}$ (Figure 2). Except for the patients 39,41 (recently diagnosed) and 30 (remission), all of them were in treatment.

We applied multivariate analysis to evaluate the dispersion of MDA levels between the groups. The dendrogram plot clearly distinguishes two main clusters using the Euclidean distances, one composed of HP and the other of ALL (Figure 3a). The principal component analysis score plot (PCA) also indicated clear discrimination between both groups. A separation trend for HP and ALL patients was observed with $100 \%$ of the data variability explained by principal component 1 (PC1) and 2 (PC2) (Figure $3 \mathrm{~b}$ ), which shows that MDA determination was capable to distinguish the groups. The same differentiation was also observed by Battisti et al. ${ }^{11}$

Oxidative stress in humans is also related to the existing biological variability and the various factors such as age, gender, ethnicity, and body mass index, ${ }^{27}$ however, these parameters were excluded from the present study because the number of samples was not large enough. Nevertheless, the MDA values alone cannot be used as criteria of normality in toxicological analysis. It can only identify whose patients had significant difference from the average value when compared to the control group.
It is known that the risk-based stratification of patients used to identify the features affecting prognosis, could be differentiated in low- and high-risk, in which the main difference is the toxicity of the treatment. The classification

(a)

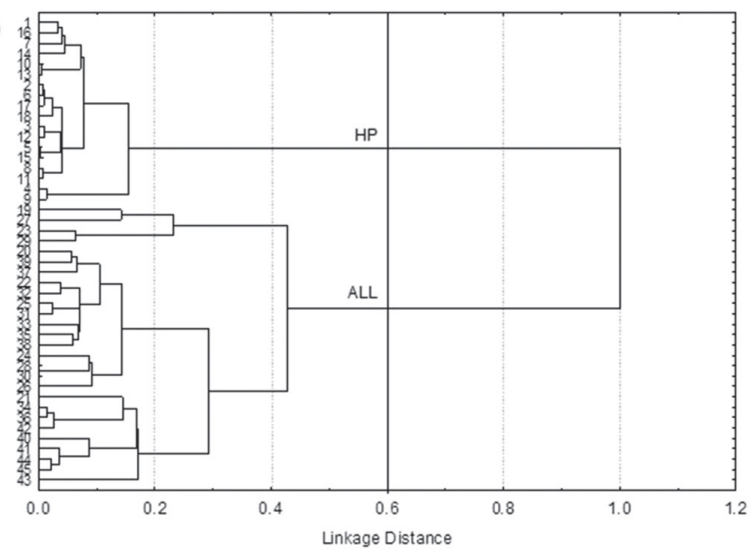

(b)

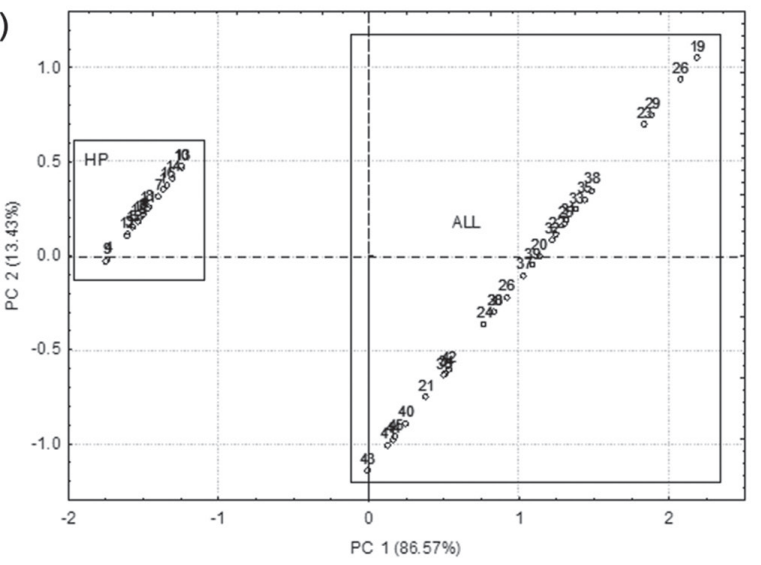

Figure 3. Application of chemometrics on malondialdehyde (MDA) levels from healthy (HP) and acute lymphoblastic leukemia (ALL) patients measured by RP-HPLC-UV-Vis (reversed phase high performance liquid chromatography with ultraviolet-visible detection) method. (a) Dendrogram plot from hierarchical clustering analysis (HCA); and (b) principal components analysis (PCA) score plot showing the separation of HP and ALL groups. 
is affected, for example, by age and white blood cells (WBC) count. ${ }^{6,28-30}$ The biochemical parameters obtained from ALL patient's charts, such as the risk (R), leukocytes (LE), blasts (BL), erythrocyte (E), hemoglobin (HG), and platelets (PL), are described in Table 2.

The ALL group studied showed differences in the count of LE (1900 to $119000 \mathrm{~mm}^{3}$ ), $\mathrm{HG}$ (4.80 to $16.00 \mathrm{~g} \mathrm{dL}^{-1}$ ), PL (8000 to $1000000 \mathrm{~mm}^{3}$ ) and presence or absence of BL (0 to $77 \%$ ) (Table 2).

In order to evaluate the relationship between biochemical parameters, MDA values and the risk stratification, it was used the same statistical approaches, the hierarchical clustering analysis, performed using only the data from 19 patients with complete charts. A separation in four clusters using the Euclidean distance was obtained (Figure 4a). The dispersion of samples in the PCA score plot was performed using the 3D projection (Figure 4b), since the use of $\mathrm{PC} 3$ was needed to explain a reasonable amount of sample variance $(60.22 \%)$.

The patients 23, 25, 27, 32, 35, 38, and 39, according to the charts, were classified as low risk, with presence of blasts, and the MDA values obtained were above the mean value $\left(2.17 \mu \mathrm{mol} \mathrm{L}^{-1}\right)$ (Table 2). We could observe that samples 20, $29,30,39$ and $40(\bullet)$ were allocated in the negative quadrant of PC 3, while samples 19, 22, 28, 32 and 42 (॰) were in the positive quadrant, showing the separation of groups. The sample $37(\bullet)$, which showed the highest count of LE, was separated from the others. The samples $23,25,27,35,36$, 41, 43 and 44, with green dots ( $\bullet$, were disposed on the negative quadrant of PC1 (Figure 4b).

Table 2. Malondialdehyde plasma levels determined by RP-HPLC-UV-Vis and biochemical parameters data obtained by routine clinical assays from patients' charts

\begin{tabular}{|c|c|c|c|c|c|c|c|}
\hline Patient $^{\mathrm{a}}$ & $\mathrm{R}^{\mathrm{b}}$ & $\mathrm{MDA} /(\mu \mathrm{mol} \mathrm{L}-1)$ & $\mathrm{LE} / \mathrm{mm}^{3}$ & $\mathrm{BL} / \%$ & $\mathrm{E} / \mathrm{mm}^{3}$ & $\mathrm{HG} /\left(\mathrm{g} \mathrm{dL}^{-1}\right)$ & $\mathrm{PL} / \mathrm{mm}^{3}$ \\
\hline $19 \mathrm{M}$ & $\mathrm{H}$ & 3.67 & 5900 & 0 & 5.28 & 14.00 & 360000 \\
\hline $20 \mathrm{M}$ & $\mathrm{H}$ & 2.37 & 8680 & 0 & 5.00 & 16.00 & 183900 \\
\hline $21 \mathrm{M}$ & $\mathrm{H}$ & 1.45 & 3600 & 0 & - & 8.70 & 1000000 \\
\hline $22 \mathrm{M}$ & $\mathrm{H}$ & 2.52 & 1900 & 0 & 4.18 & 12.69 & 327000 \\
\hline $23 \mathrm{~F}$ & $\mathrm{~L}$ & 3.24 & 24400 & 8 & 2.81 & 7.57 & 41000 \\
\hline $24 \mathrm{M}$ & $\mathrm{H}$ & 1.93 & - & 0 & - & - & - \\
\hline $25 \mathrm{M}$ & $\mathrm{L}$ & 2.59 & 11100 & 63 & 1.86 & 5.09 & 21000 \\
\hline $26 \mathrm{~F}$ & $\mathrm{H}$ & 2.11 & - & 0 & - & - & - \\
\hline $27 \mathrm{M}$ & $\mathrm{L}$ & 3.53 & 2400 & 12 & 3.05 & 9.70 & 55000 \\
\hline $28 \mathrm{M}$ & $\mathrm{H}$ & 2.01 & 1700 & 0 & 3.23 & 10.14 & 304000 \\
\hline $29 \mathrm{~F}$ & $\mathrm{H}$ & 3.30 & 3100 & 48 & 4.37 & 14.25 & 157000 \\
\hline $30 \mathrm{M}$ & $\mathrm{H}$ & 2.01 & 7800 & 0 & 5.02 & 15.63 & 222000 \\
\hline $31 \mathrm{M}$ & $\mathrm{H}$ & 2.61 & 6700 & 0 & 4.81 & - & 189000 \\
\hline $32 \mathrm{~F}$ & $\mathrm{~L}$ & 2.48 & 2930 & 32 & 2.28 & 6.57 & 371100 \\
\hline $33 \mathrm{~F}$ & $\mathrm{~L}$ & 2.68 & 13600 & 0 & 4.28 & - & 232000 \\
\hline $34 \mathrm{~F}$ & $\mathrm{~L}$ & 1.61 & 4400 & 0 & 4.60 & 12.50 & - \\
\hline $35 \mathrm{~F}$ & $\mathrm{~L}$ & 2.75 & 13200 & 74 & 2.56 & 6.90 & 11000 \\
\hline $36 \mathrm{M}$ & $\mathrm{L}$ & 1.59 & 2300 & 0 & 2.53 & 6.26 & 21000 \\
\hline $37 \mathrm{~F}$ & $\mathrm{H}$ & 2.25 & 119000 & 0 & 1.98 & 6.72 & 55000 \\
\hline $38 \mathrm{~F}$ & $\mathrm{~L}$ & 2.81 & - & 4 & - & - & - \\
\hline $39 \mathrm{M}$ & $\mathrm{L}$ & 2.32 & 5200 & 25 & 2.88 & 7.60 & 144000 \\
\hline $40 \mathrm{~F}$ & $\mathrm{~L}$ & 1.28 & 4600 & 0 & 3.01 & 9.02 & 114000 \\
\hline $41 \mathrm{~F}$ & $\mathrm{H}$ & 1.14 & 39650 & 75 & 3.11 & 8.80 & 31000 \\
\hline $42 \mathrm{M}$ & $\mathrm{L}$ & 1.63 & 8100 & 77 & 3.53 & 10.20 & 383000 \\
\hline $43 \mathrm{M}$ & $\mathrm{L}$ & 0.97 & 1900 & 0 & 3.09 & 8.20 & 8000 \\
\hline $44 \mathrm{~F}$ & $\mathrm{~L}$ & 1.17 & 20700 & 72 & 1.96 & 4.80 & 14000 \\
\hline $45 \mathrm{~F}$ & $\mathrm{~L}$ & 1.19 & - & 0 & - & - & - \\
\hline
\end{tabular}

${ }^{\mathrm{a}} \mathrm{F}$ : female; M: male; ${ }^{\mathrm{b}} \mathrm{H}$ : high risk; L: low risk. R: risk. RP-HPLC-UV-Vis: reversed phase high performance liquid chromatography with ultraviolet-visible detection; MDA: malondialdehyde; LE: leukocytes; BL: blasts; E: erythrocyte; HG: hemoglobin; PL: platelets. 
(a)

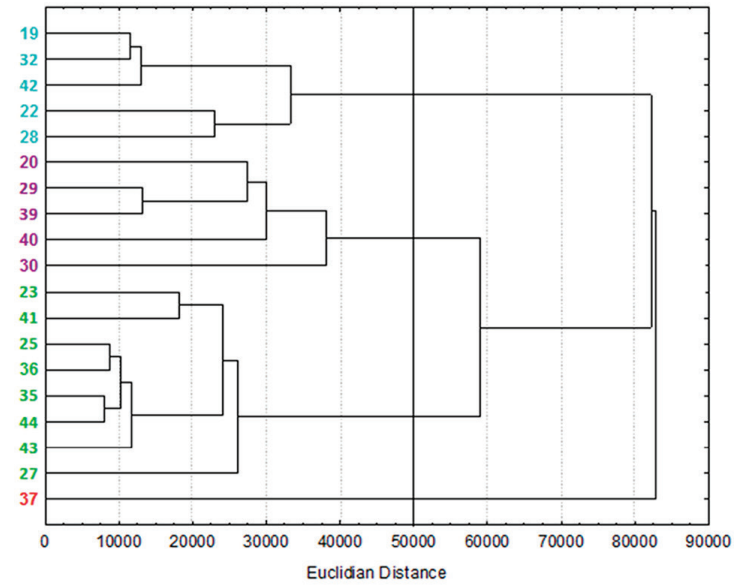

(b)

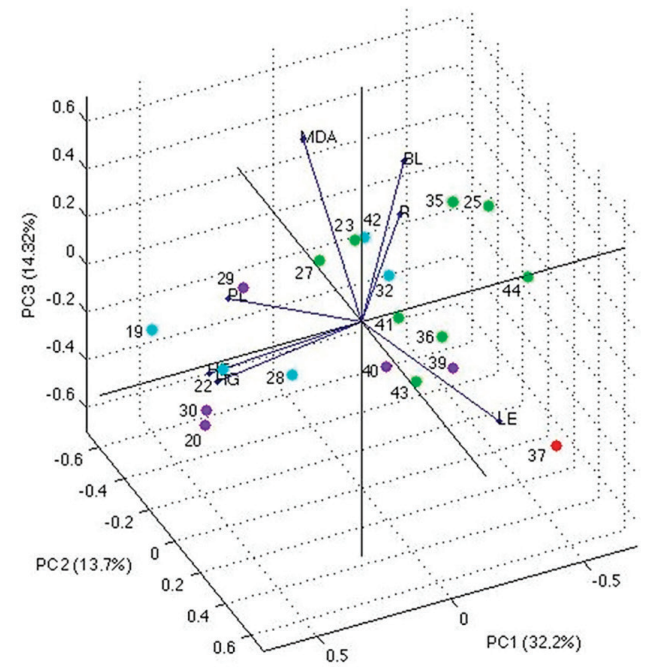

Figure 4. Application of chemometrics on MDA levels measured by RP-HPLC-UV-Vis method and biochemical parameters data obtained by routine clinical assays from patients' charts with acute lymphoblastic leukemia (ALL). (a) Dendrogram plot from hierarchical clustering analysis (HCA), and (b) principal components analysis (PCA) score plot. MDA: malondialdehyde; RP-HPLC-UV-Vis: reversed phase high performance liquid chromatography with ultraviolet-visible detection; LE: leukocytes; BL: blasts; E: erythrocyte; HG: hemoglobin; PL: platelets; R: risk; PC1: principal component 1; PC2: principal component 2; PC3: principal component 3 .

The dispersion of variables (Figure $4 \mathrm{~b}$ ) states the relationship observed in majority of cases. The patients that have a high percentage of blasts and leukocytes (patients $23,25,35,37,41$, and 44) (Table 2) are allocated, mostly in the negative quadrant of $\mathrm{PC} 1$, as well as the patients 27 , 32 and 39 (Figure 4b).

The MDA values when associated to other data from the charts contributed with separation at the PC3. All patients with concentration of MDA higher than mean value $\left(2.17 \mu \mathrm{mol} \mathrm{L}^{-1}\right)$ were allocated in the positive side of PC3, and most of them were stratified in the charts as high risk. Likewise, the low risk showed values below the average. It is important to highlight that the stratification risk was directly related to biochemical parameters, mainly the WBC, thus the contribution of MDA values alone was not so effective in the separation of the ALL patients. ${ }^{6,30}$ Nevertheless, despite the number of patients was not so large, it was possible to observe a relation with the risk segregation and the differences in MDA values obtained for the ALL group, indicating that this biomarker may assist in the diagnosis and stratification.

\section{Conclusions}

Analysis of oxidative stress using the MDA as a biomarker proved to be adequate in the study of acute lymphoblastic leukemia in young patients, since the levels of individuals diagnosed with ALL differed significantly from healthy controls, indicating a possible direct connection between the disease and lipid peroxidation observed in the organism.

In addition, the use of multivariate analysis turned possible to observe a relationship between MDA and biochemical data from the patient's charts with the risk classification of patients, thus being one more parameter to be evaluated during the treatment.

\section{Acknowledgments}

The authors would like to thank the patients who volunteered for this study and express their gratitude to Marla K. Amarante and Maria Angélica E. Watanabe for supplying the samples and their colaboration, and to Maria Josefa S. Yabe for the statistical support. This study was supported by the Coordenação de Aperfeiçoamento de Pessoal de Nível Superior (CAPES) - PROCAD (process No. 3007/2014).

\section{References}

1. Reis, R. D. S.; de Camargo, B.; Santos, M. D. O.; Moreira, J.; Olivera, D.; Silva, F. A.; Pombo-de-Oliveira, M. S.; Pediatr. Blood Cancer 2011, 56, 58.

2. Farias, M. G.; Castro, S. M.; J. Bras. Patol. Med. Lab. 2004, 40, 91.

3. Perim, A. L.; Guembarovski, R. L.; Oda, J. M. M.; Lopes, L. F.; Ariza, C. B.; Amarante, M. K.; Fungaro, M. H. P.; Oliveira, K. B.; Watanabe, M. A. E.; Mol. Biol. Rep. 2013, 40, 4591.

4. Rodrigues, K. E.; Camargo, B.; Rev. Assoc. Med. Bras. 2003, 49, 29.

5. Yue, Q.; Xiong, B.; Chen, L.; Chen, Y.; Bu, F.; Liu, X.; Cheng, F.; Biomed. Pharmacother. 2015, 69, 76.

6. Plasschaert, S. L. A.; Kamps, W. A.; Vellenga, E.; de Vries, E. G. E.; de Bont, E. S. J. M.; Cancer Treat. Rev. 2004, 30, 37.

7. Crans, H. N.; Sakamoto, K. M.; Leukemia 2001, 15, 313. 
8. Ferrara, F.; Lancet Oncol. 2004, 5, 443.

9. Löwenberg, B.; Best Pract. Res., Clin. Haematol. 2001, 14, 65.

10. Halim, N. H. A.; Mashor, M. Y.; Hassan, R.; Int. J. Res. Rev. Comput. Sci. 2011, 2, 971.

11. Battisti, V.; Maders, L. D. K.; Bagatii, M. D.; Santos, K. F.; Spavanello, R. M.; Maldonado, P. A.; Brulé, A. O.; Araújo, M. C.; Schetinger, M. R. C.; Morsch, V. M.; Clin. Biochem. 2008, $41,511$.

12. Almondes, K. G. S.; Oliveira, T. F.; Siviero-Miachon, A. A.; Lee, M. L. M.; Rondó, P. H. C.; Loureiro, A. P. M.; Spinola-Castro, A. M.; Cozzolino, S. M. F.; Nutrition 2014, 30, 563.

13. Zhou, F.; Zhang, W.; Wei, Y.; Zhou, D.; Leuk. Res. 2007, 31, 387.

14. Klaunig, J. E.; Kamendulis, L. M.; Annu. Rev. Pharmacol. Toxicol. 2004, 44, 239.

15. Rahman, T.; Hosen, I.; Islam, M. M. T.; Shekhar, H. U.; Adv. Biosci. Biotechnol. 2012, 3, 997.

16. Chang, D.; Sha, Q.; Zhang, X.; Liu, P.; Rong, S.; Han, T.; Liu, P.; Pan, H.; PLoS One 2011, 6, e27218.

17. Dalle-Donne, I.; Rossi, R.; Colombo, R.; Giustarini, D.; Milzani, A.; Clin. Chem. 2006, 52, 601.

18. Vasconcelos, S. M. L.; Goulart, M. O. F.; Moura, J. B. F.; Manfredine, V.; Benfato, M. S.; Kubota, L. T.; Quim. Nova 2007, 30, 1323.

19. Moselhy, H. F.; Reid, R. G.; Yousef, S.; Boyle, S. P.; J. Lipid Res. 2013, 54, 852.
20. Grotto, D.; Maria, L. S.; Valentini, J.; Paniz, C.; Schmitt, G.; Garcia, S. C.; Pomblun, V. J.; Rocha, J. B.; Farina, M.; Quim. Nova 2009, 32, 169.

21. de las Heras, A.; Schoch, A.; Gibis, M.; Fischer, A.; Eur. Food Res. Technol. 2003, 217, 180.

22. Bastos, A. S.; Loureiro, A. P. M.; Oliveira, T. F.; Corbi, S. C. T.; Caminaga, R. M. S.; Júnior, C. R.; Orrico, S. R. P.; Anal. Biochem. 2012, 423, 141.

23. Agência Nacional de Vigilância Sanitária (ANVISA); Guia para Validação Métodos Analíticos e Bioanalíticos, Resolução RE No. 899, 2003.

24. STATISTICA, 8.0, StatSoft, Tulsa, USA, 2007.

25. MATLAB, 7.0, MathWorks, Natick, Massachusetts, 2005.

26. http://www.hplc.eu/Downloads/ACE_Guide_BufferSelection. pdf, accessed in May 2017.

27. Kuno, R.; Roquetti, M. H.; Gouveia, N.; Rev. Panam. Salud Pública 2010, 27, 74.

28. Cooper, S. L.; Brown, P. A.; Pediatr. Clin. North Am. 2015, 62, 61.

29. Usvasalo, A.; Elonen, E.; Saarinen-Pihkala, U. M.; Räty, R.; Harila-Saari, A.; Koistinen, P.; Koistinen, E. R.; Knuutila, S.; Hollmén, J.; Leuk. Res. 2010, 34, 1476.

30. Pui, C.-H.; Robison, L. L.; Look, A. T.; Lancet 2008, 371, 1030.

Submitted: June 28, 2017 Published online: September 29, 2017 